بسم الله الرحمن الرحيم

\title{
كلمهة التصربز
}

Editorial Words

Kata Pengantar

الحمدلله الذي أنعم علينا بنعمه وجعل للإنسان عينين وشفتين، وأنزل القرآن الكريم بلسان عربي مبين ليكون هاديا ومنيرا للعاملين، والصلاة والسلام على رسوله المصطفى الأمين وآله وصحبه أجعين، وبعد. ففي هذه الإطلالة الجديدة من العدد الأول للسنة الخامسة بدأت المجلة تنتشر انتشارا واسعا في ربوع العالم العربي والإسلامي وسائر العالم في كل القارات، إذ يتواصل معنا كثير من الباحثين الناطقين بالعربية من شتى الدول، من أجل النشر في هذه البحلة لما لها من سمعة علمية وشهرة عالمية أخذت تجذب كثيرا من العلماء والأدباء واللغويين للنشر فيها في مجالات عدة لغوية أو أدبية أو في تعليم اللغة لغير الناطقين بها والدراسات التقابلية وغيرها من بحالات اللسانيات التطبيقية. بدأ العدد بتناول موضوع الدراسات اللغوية، إذ أشار البحث الموسوم: "التأثر والتأثير اللغوي بين اللغة العربية والتركية"، إلى تأثير اللغة العربية في اللغة التركية، وتأثرها بها أيضا، وقد توصلت الدراسة إلى أن ثمّة كلمات عربية قد إند دخلت إلى التركية مع الحفاظ على معانيها، وكلمات عربية دخلت إلى التركية بنفس اللفظ واختلفت بالمعنى، وكلمات عربية بصيغة الجمع تحولت إلى صيغ مفردة بالتركية مع الحفاظ على المعنى، وكلمات بصيغة الجمع في اللغة العربية، ويضاف إليها أيضا صيغة الجمع باللغة التركية (lar)، وكلمات عربية في صيغة الجمع، تحولت إلى صيغة المفرد باللغة التركية مع الحفاظ على المعنى. وتناول المقال المعنون: "الترجمة الآلية إلى اللغة العربية. صعوبات وتحديات (ترجمة غوغل) مثالا"، حيث يهدف هذا البحث إلى دراسة الأخطاء النحوية واللغوية في الترجمة الآلية الخاصة بـ" ترجمة غوغل"، معرجاً في سبيل ذلك إلى أصل الترجمة الآلية، وأهم مصطلحاها وأنواعها، ومشكلة الترجمة إلى العربية عمومًا، وعالج آلية "ترجمة غوغل" واختبارها، ومعرفة أسباب الأخطاء، وتصنيف مثل هذه الأخطاء في بحموعات، مع وضع التعليق المناسب عليها، ثم تقديم اقتراحات لمعالجة مثل هذه الأخطاء، وفي الخاتمة يتم تلخيص نتائج 
الدراسة. وفي المقال: "معايير اختيار النصوص الأدبية العربية في المرحلة الثانوية الدينية العالية الماليزية: دراسة تقويمية"، تناول الباحثان النصوص الأدبية التي يدرسها الطلبة في تلك المادة، إذ لم يكن اختيارها

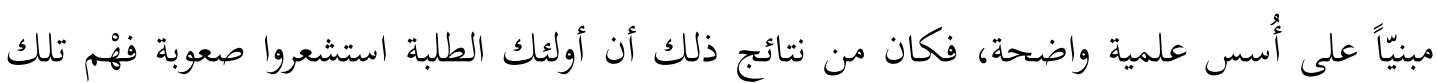
النصوص وعسنر تعلّمها، لأن تلك النصوص لا تشجّعهم على الاستمرار في قراءقا، لذا أبرز البحث جوانب القصور في اختيار تلك النصوص من ناحية الشكل والمحتوى، أما الشكل فسيُكتشف فيه جانب اختيار المفردات والتراكيب وحجم النص، بينما المحتوى سيُبر فيه الجحانب الثقافي والنفسي والتربوي لمضامين تلك النصوص، واقترح البحث بعض النماذج المختارة من النصوص الأدبية العربية التي تتناسب مع مستوى طلبة هذه المرحلة. وتناول البحث المعنون: "تقويم برنامج تعليم اللغة العربية للكبار الناطقين بغير العربية من وجهة نظرهم: الجامعة الإسلامية العالمية بماليزيا نموذجاً"، عبر المنهج الوصفي الاستقرائي التحليلي الإجابة عن السؤال الرئيس: ما مدى فعالية برنامج التعليم للمتعلمين؟ وقد طرح الباحثان استبياناً على عينة من الدارسين قدرها بـ دارساً، وقد أفضت الدراسة إلى نتائج مهمة، من أهمها: أن البرنامج فعّال، والأمور التي يراعيها هذا البرنامج من زمن التدريس، ومكانه، وهيئة التدريس، وعدد المتعلمين في الفصول الدراسية، والمواد التعليمية، وطرق التعليم ووسائله، ورسوم التعليم تشبع حاجات المتعلمين وميولمم، ويقبلون على الدراسة بانشراح، غير أن الباحثين يوصيان بإعادة النظر في بعض النواحي المتعلقة بطرق التعليم، واستخدام وسائله من أجل تطوير البرنامج. وأخحيرا تناولت الباحثة هيام المعمريّ في مقالها: "بتربة تفعيل اللّغة العربيّة والتّفاعل معها على المستوى العربيّ والإسلاميّ: دراسة تحليليّة"، موضوع فكرة حملة (لُغتي هُوِيَّي)؛ لتفعيل اللّغة العربيّة والتّفاعل معها. وأطلقتها هيام

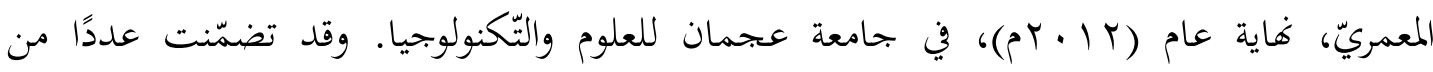
الأنشطة والفعاليات المتنوّعة؛ كإقامة النّدوات، والمسرحيّات، والمعارض، والمسابقات، والمطويّات، والمنشورات، ولقيت الحملة إقبالا كبيرًا، عند افتتاح حفلها، من داخل الجحامعة وخارجها. وفي العام التّالي انطلقت الحملة في دورتما الثّانية، برعاية رئيس دائرة التّمية السّياحيّة بعجمان. وللحملة شعارها المصمّمم لما، ومواقع إلكترونيّة وصفحات تواصل اجتماعيّة خاصّة بها، وصلت أعداد المتفاعلين معها والمتابعين لما المئات وهي في تزايد مطرّد. وما زال العمل بها مستمرَّا. وفي بحال الدراسات الأدبية ثمة مقالات بدأت الحديث عن التراث القديم عبر مقال موسوم: "كتاب البيان والتبيين من منظور النقد العربي الحديث: مقاربة منهجية في أنماط التلقي"، وقد تناول الباحث فيه خلخلة بعض البديهيات الفكرية أو الأدبية التي راجت حول الجاحظ؛ بمعنى كيف فهم وقارب الباحث عبد العزيز حمودة الدرس الجاحظي، وكيف طبق كلامه، وماذا أضاف إليه، وماذا صنع به الزمن الحداتي. وتوصلت دراسته إلى أن النّهج التأليفي الجاحظي فن التّدوين يجعل استنباط أفكاره 
ومعارفه النّقديّة تحتاج إلى باحث محبّ عاشق لهذا التّراث، يصبر على مشاقه، ويملك خبرة رائعة بطريقته، ويكون حذراً فن كلّ ما يقرؤه، ولكن لو صبرنا على هذا سنخرج بنتائج وملاحظات نقديّة مبهرة؛ لأن للتّراث الجاحظيّ قداسته التى تجعله يتمنع على من لا يُقدِّره حقّ قدره، ولا يخرج لآلئه إلا لمن غاص كثيرا في أعماقه، وقتها يهبه الكثير والكثير من ثرواته اللغويّة والنّقديّة. وفي تتبع قضايا التراث بينت الباحثتان في مقالمما بعنوان: "نظرات نقدية في (رسالة التوابع والزوابع)"، المواقف النقدية لدى ابن شهيد الأندلسي الذي صوّر رحلة خيالية التقى فيها توابع الشعراء والكتاب العرب القدامى، وأجرى بينهم حوارات ومناظرات، كشفت منازهم الأدبية، وفي الوقت نفسه التمس فيها التقدير الذي افتقده بين معاصريه، في دنيا الخيال أو عالم الجمن. وبرز فيها شاعراً وكاتباً فذاً يفوقهم، وناقداً يحذو حذو النقاد المشارقة بما قدّمه من وقفات ونظرات نقدية، عالج فيها جملة من القضايا النقدية التي كانت مدار بحث

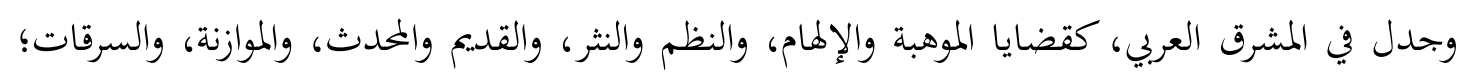

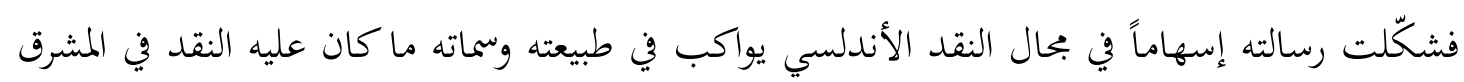
العربي. وفي بحال البحث العلمي الصارم وعناصره بيّن الباحث في مقاله الذي بعنوان: "اللغة العلمية بين التعريب والتأليف" التعريب والتأليف، وطبيعة العلاقة الجحلية بينهما في صياغتهما للغة العلم، ودورهما في تطوير أدوات اللغة واستيعاب المضامين العلمية ومصطلحاقا، ونشر الكتاب العلمي العربي. وتوصلت دراسته إلى أن لغة العلم لا تطلب مستوى من الأداء اللغوي شبيهاً بالمستوى الأدبي، وأن لغة العلم ليست كلها مصطلحات، وأنّ ما يزيد على (1/1\%) من كلمات النصوص العلمية هي من الثروة اللفظية التي يشترك فيها أغلب المتعلمين، وأن العربية تمتلك كثيراً من المصطلحات قامت بوضعها المحامع والمؤسسات العلمية والأساتذة، وأنّ اللغة العلمية والعلماء قد أسهموا في وضع المصطلح العلمي واستخدامه وشيوعه ونشره، وأن التعريب والتأليف في العلم قد أسهما في صناعة لغة للعلم في العصر

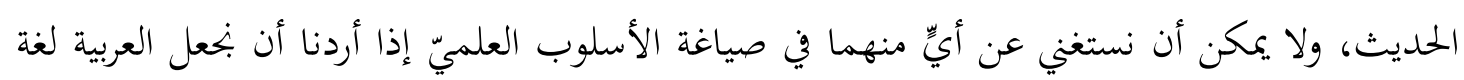
للعلم. وفي التراث القديم قيم عائلية أشار إليها القدامى في أدبياهم، إذ تناول البحث: "القيم العائلية في المصادر التراثية وأثر التطور الحضاري"، قضايا الأدب وعلاقته بالحياة إلى القيم الأساسية الفردية والعائلية (الأسرية) التي يختزها التراث الحضاري في ما يحمله من رصيد ثقافي وأخلاقي وديني يسهم في إضاءة تفكير الناس وبناء مُثُلهم وتوجهاقهم الإنسانية. وحاول في دراسته أن يقارب هذا الميدان انطلاقاً من الرغبة في عدم الاكتفاء بما ورد في ديوان الشعر العربي والتراث القديم من قيم الكرم والفروسية والنجدة،

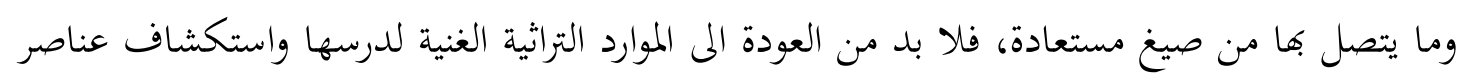
الثبات والتغير التي واجهتها هذه القيم الفردية والأسرية، خصوصاً بعد ظهور الإسلام وما أحدثه في تهن المفاهيم الدينية الجحديدة وفي الفروض والعقائد والسلوكيات، وما أحدثه بعد الفتوحات وتعايش الحضارات والشعوب في العواصم المختلفة. وقد أدخلت هذه النهضة معطيات ثقافية وحضارية رفدت 
تلك الأسس بمفاهيم وعادات جديدة شخصية وعائلية واجتماعية حركت مظاهر التفكير والحياة والسلوك والتعبير الأدبي والفني، مما لا نزال نشهد تطوراته السوسيولوجية إلى يومنا هذا. وأخيراً تناول

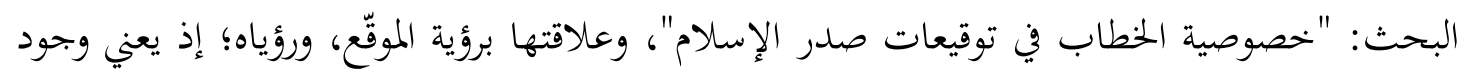

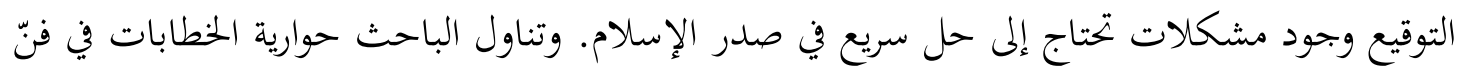

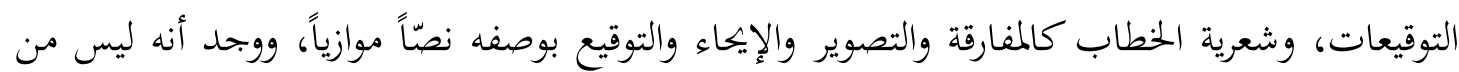

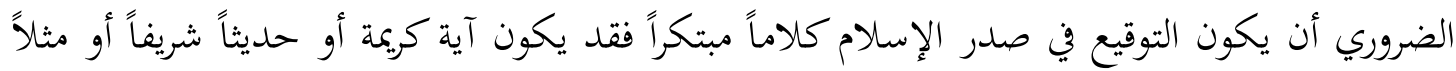

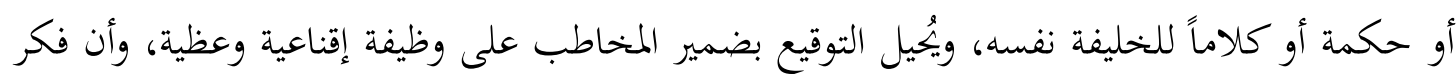

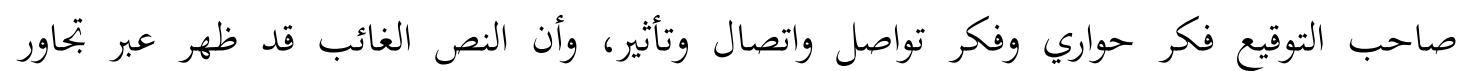

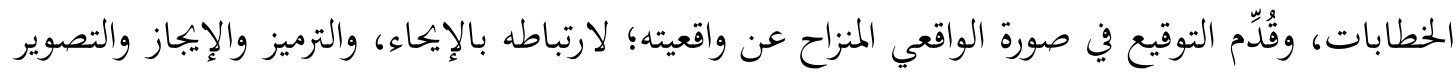

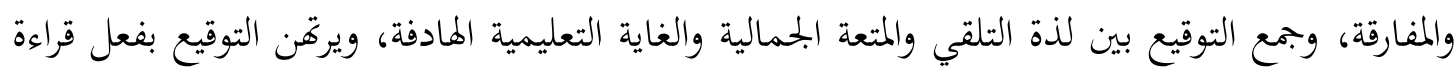

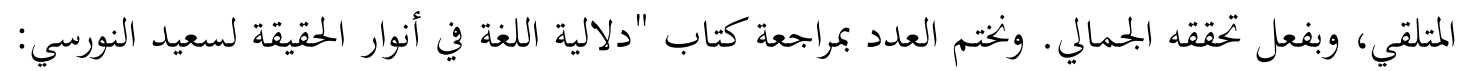

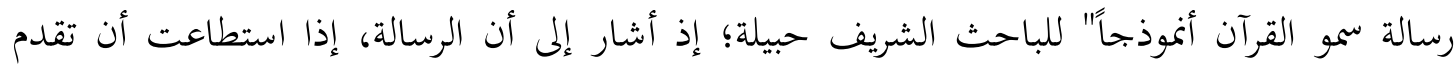

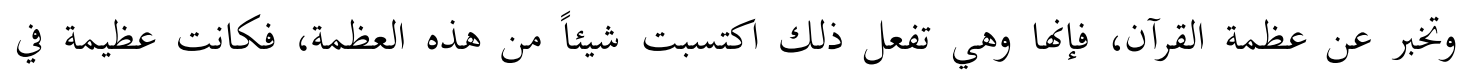

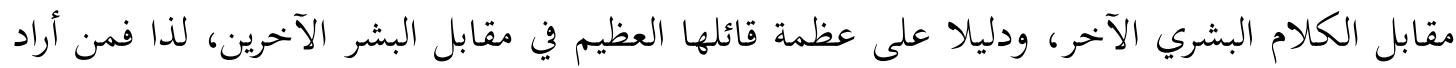
أن يكون عظيماً فعليه أن يشرب من نبع العظمة الأصيل وهو القرآن العظيم كلام الله.

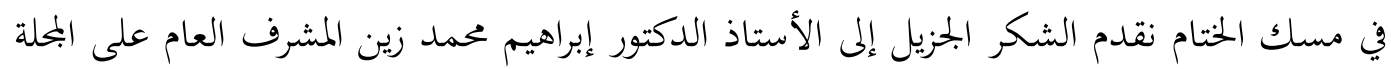
وعميد كلية معارف الوحي والعلوم الإنسانية على الدعم الذي قدمه للمجلة في كل الجوانب، ولأعضاء هيئة التحرير على جهودهم في التحسين والتطوير، وللباحثين الذي أثروا المجلة بمقالاتمم القيمة الثّرة،

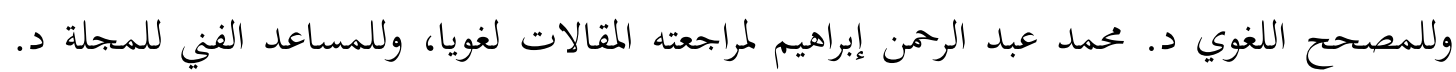

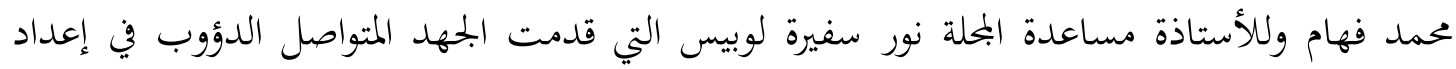
العدد طباعة وتنضيدا، وآخر دعوانا أن الحمد لله رب العالمين.

رئيس التحرير

الأستاذ المشارك د. عاصم شحادة علي 